\title{
Avaliação da dinâmica do desflorestamento legal no estado do Amapá com a utilização de geotecnologias
}

O estado do Amapá é o mais conservado do Brasil, com $97 \%$ de cobertura florestal intacta, um total de $73 \%$ do território do Estado corresponde às áreas protegidas que incluem unidades de conservação e terras indígenas ou quilombolas. No entanto, nos últimos anos não houve estudos técnico-científicos com o objetivo de mensurar e identificar o desmatamento autorizado no Estado, pois sem a distinção do desflorestamento ilegal do legal não é possível direcionar ações e políticas públicas aplicadas diretamente às atividades ilegais. O objetivo principal desta pesquisa foi analisar o impacto do desflorestamento ilegal no desflorestamento total do estado do Amapá nos anos de 2013 e 2014, através de ferramentas de geotecnologia. Para a análise espacial foi utilizado o Sistema de Informação Geográfica (SIG) a partir do software ArcGIS, e shapefile de áreas desflorestadas e autorizações de desmatamento, emitidas pelo órgão competente, sendo elas espacializadas e comparadas. Os resultados mostraram que nos anos de 2013 e 2014 o desflorestamento não autorizado chegou a 50,13\%, que correspondeu a 3.493,58 hectares, ou seja, mais da metade do desflorestamento detectado pela Secretaria de Estado e Meio Ambiente foi realizado ilegalmente no estado do Amapá. Ficou evidente que a geotecnologia é uma ferramenta muito útil devido à sua funcionalidade, demonstrando a possibilidade e necessidade da aplicação de geoprocessamento para a análise do desmatamento legal, com a espacialização das autorizações de desmatamento.

Palavras-chave: Atividades llegais; Autorizações de Desmatamento; Geoprocessamento.

\section{Evaluation of the dynamics of legal deforestation in the Amapá state with the use of geotechnologies}

\begin{abstract}
The state of Amapá is the most conserved in Brazil, with $97 \%$ of forest cover intact, a total of $73 \%$ of the state's territory corresponds to protected areas that include conservation units and indigenous or quilombola lands. However, in recent years there have been no technical-scientific studies with the objective of measuring and identifying the deforestation authorized in the State, since without distinction of illegal deforestation it is not possible to direct actions and public policies directly applied to illegal activities. The main objective of this research was to analyze the impact of illegal deforestation on the total deforestation of the state of Amapá in the years of 2013 and 2014 through geotechnology tools. For the spatial analysis, the Geographic Information System (GIS) was used from the ArcGIS software, and shapefile of deforested areas and deforestation authorizations, issued by the competent agency, being spatialized and compared. The results showed that in the years of 2013 and 2014 the unauthorized deforestation reached 50.13\%, which corresponded to 3,493.58 hectares, that is, more than half of the deforestation detected by the State Department and Environment was carried out illegally in the state of Amapá. It was evident that geotechnology is a very useful tool due to its functionality, demonstrating the possibility and necessity of the application of geoprocessing for the analysis of legal deforestation, with the spatialisation of deforestation authorizations.
\end{abstract}

Keywords: Illegal Activity; Deforestation Authorizations; Geoprocessing.

Topic: Tecnologia, Modelagem e Geoprocessamento

Received: 14/12/2017

Approved: $24 / 01 / 2018$

Reviewed anonymously in the process of blind peer.

José Douglas Monteiro da Costa (iD)

Universidade Federal do Amapá, Brasil

http://lattes.cnpq.br/7756200053701768

http://orcid.org/0000-0002-1710-7686

cientistaambiental2012@gmail.com

Sávio Luis Carmona Santos

Universidade Federal do Amapá, Brasil

http://lattes.cnpq.br/4120393378913333

ssaviox@gmail.com

Cláudia Funi

Universidade Federal do Amapá, Brasi

http://lattes.cnpq.br/3723834990118217

claudiafuni@gmail.com

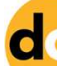

DOI: 10.6008/CBPC2179-6858.2018.002.0024
Referencing this:

COSTA, J. D. M.; SANTOS, S. L. C.; FUNI, C.. Avaliação da dinâmica do desflorestamento legal no estado do Amapá com a utilização de geotecnologias. Revista Ibero Americana de Ciências Ambientais, v.9, n.2, p.291-303, 2018. DOI: http://doi.org/10.6008/CBPC2179$\underline{6858.2018 .002 .0024}$ 


\section{INTRODUÇÃO}

Primeiramente é necessário definir desmatamento, pois a aplicação deste conceito engloba diferentes áreas do conhecimento, de estudos científicos às legislações ambientais. De acordo com Brasil (2003), o desmatamento é a atividade que tem como objetivo a descaracterização da vegetação nativa de uma determinada área, com a finalidade de implantação de projetos de assentamento, atividades agropecuárias, industriais, florestais, de geração e transmissão de energia, de mineração e de transporte.

O desflorestamento realizado sem autorização emitida pelos órgãos ambientais competentes é denominado de ilegal ou não autorizado, e traz consequências negativas ao meio ambiente. No estado do Amapá, a agricultura é a atividade responsável por grande parte do desflorestamento, sendo desenvolvida através de roças, as quais possuem um sistema de revezamento de terras, variando em uma área de no máximo 2 ha (DOMINGUES et al., 2004; AMAPÁ, 2009).

A maior pressão de desflorestamento se concentra em torno dos eixos das rodovias BR-156 e BR210, no sentido dos municípios de Macapá-Oiapoque. A expansão da pecuária e da agricultura ocasionam queimadas, junto com o avanço desenfreado da exploração madeireira ilegal e os projetos de assentamentos (AMAPÁ, 2014; LEMOS et al., 2011).

Todas essas atividades causadoras do desflorestamento têm levado às consequências severas contra o meio ambiente, ao setor econômico e a sociedade (BRASIL, 2003; MMA, 2004). Para Kitamura (1994) o desflorestamento, além de apresentar consequências no âmbito local e regional, afeta também o planeta, resultando em mudanças climáticas causadas pela perda do revestimento florestal, o efeito estufa causado pela queima de madeira, aumento da sedimentação dos rios, erosão, degradação do solo e perda da biodiversidade.

Um dos maiores desafios atuais consiste em diferenciar o desflorestamento ilegal do legal, para que se possa efetivamente extinguir o ilegal e promover políticas públicas para reduzir a supressão legal, sem prejuízo do desenvolvimento local. O desflorestamento legal, diferente das atividades ilegais contra a biodiversidade, tem o objetivo em conciliar os aspectos ambientais com o econômico de uma sociedade. Todavia, deve ser uma atividade planejada, monitorada e fiscalizada pelo Estado, para não comprometer o meio ambiente e o interesse público.

Com a Lei Federal № 11.284, de 2 de março de 2006, a gestão florestal passou a ser atribuição do Estado, executada pela Secretaria de Meio Ambiente do Estado do Amapá (SEMA) e pelo Instituto de Meio Ambiente e Ordenamento Territorial do Estado do Amapá (IMAP). As autorizações são emitidas pelo IMAP usando o Sistema de Produtos Florestais (SISPROF) do Instituto Brasileiro do Meio Ambiente e dos Recursos Naturais Renováveis (IBAMA), em conformidade com a Instrução Normativa № 3, de 4 de março de 2002 IBAMA e a Instrução Normativa № 75, de 25 de agosto de 2005-IBAMA, que tratam de autorizações de desmatamento.

De acordo com relatório do Sistema de Produtos Florestais (SISPROF), no período de 2002 a 2009, foi autorizada a supressão de $404 \mathrm{~km}^{2}$ de áreas de florestas no estado do Amapá (AMAPÁ, 2009). No mesmo 
período foram quantificados aproximadamente $784 \mathrm{~km}^{2}$ desmatamento no estado do Amapá através do uso de geotecnologias (INPE, 2015; AMAPÁ, 2005; 2009; 2010). Para este período a desmatamento não autorizado chegou aproximadamente a $48,5 \%$ do total de desmate detectado.

O estado do Amapá no período de 2011 e 2012 teve uma área desmatada de aproximadamente 692,2 km² (AMAPÁ, 2014). A SEMA vem utilizando desde 2011 imagens de alta resolução (RapidEye). No mesmo período o INPE identificou $93 \mathrm{~km}^{2}$ utilizando imagens de média resolução (LandSAT). A mudança na metodologia trouxe um grande avanço para o Estado, possibilitando a análise do desmatamento com maior precisão. Em contrapartida, uma taxa de desmatamento mais alta foi identificada em comparação com os anos anteriores.

Para monitorar o desmatamento legal do Estado é necessário que ocorra o monitoramento do desmatamento de todo território, pois apenas assim é possível distinguir áreas alteradas legalmente das áreas alteradas ilegalmente. Diversos institutos de pesquisa ou de governo, como SEMA e INPE, fazem o monitoramento do desmatamento utilizando diferentes insumos e metodologias. Para Florenzano (2008) o uso de geotecnologias permite que a área ambiental em análise seja estudada a partir de imagens, capazes de identificar, quantificar e interpretar áreas de desmatamento. A importância da utilização de geotecnologias está ligada com o seu alcance amplo, no que diz respeito à cobertura das áreas estudadas, e o auxílio nas leituras destas imagens para tomadas de decisões.

Sem a diferenciação do desmatamento ilegal do legal, devido à falta de estudos técnico-científicos, não é possível direcionar ações e políticas públicas aplicadas diretamente às atividades ilegais. Diante desta problemática, e com a utilização de técnicas de geoprocessamento, buscou-se nesse estudo levantar informações quantitativas das autorizações de desmatamento emitidas pelo IMAP. Partiu-se da hipótese que desflorestamento ilegal apresenta uma parcela superior no desflorestamento total no estado do Amapá. Deste modo, o objetivo principal do trabalho foi de avaliar o impacto do desflorestamento ilegal no desflorestamento total do estado do Amapá nos anos de 2013 e 2014 através de ferramentas de geotecnologia.

\section{MATERIAIS E MÉTODOS}

\section{Área de estudo}

O estado do Amapá é o mais conservado do Brasil, com 97\% de cobertura florestal intacta. Um total de $73 \%$ do território do Estado corresponde às áreas protegidas que incluem unidades de conservação e terras indígenas ou quilombolas (AMAPÁ, 2014). Situa-se na Região Norte, contabiliza cerca 669.526 habitantes e é composto por 16 municípios localizados ao longo de seus $142.828,523 \mathrm{~km}^{2}$ de extensão territorial (IBGE, 2010). 


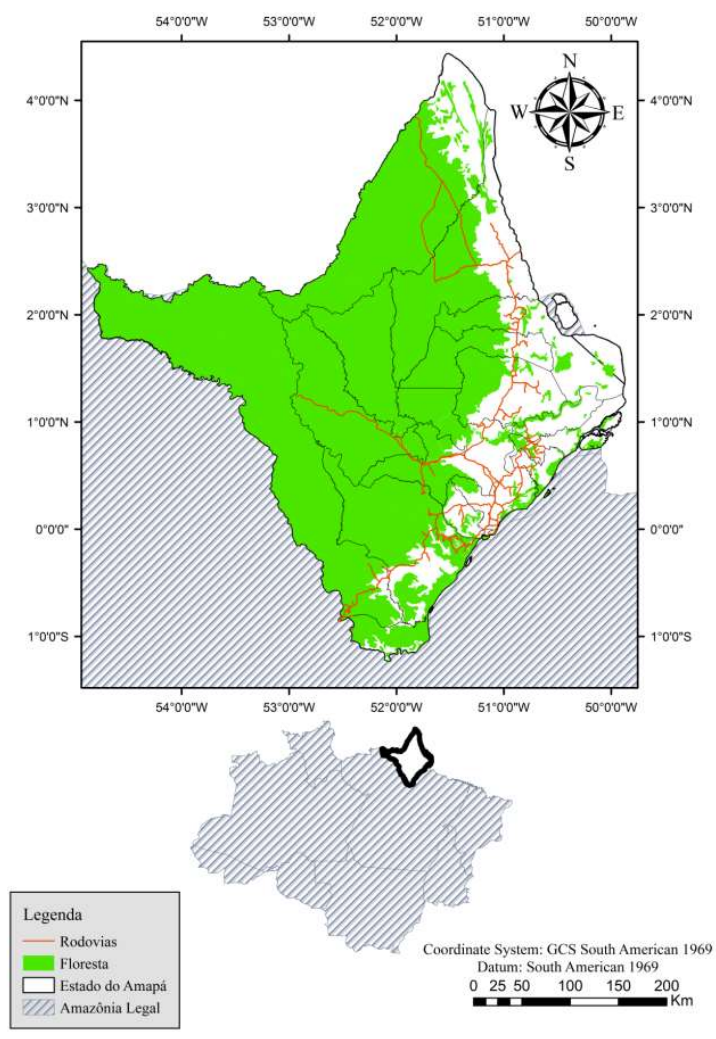

Figura 1: Localização da área de estudo - Amapá.

O clima é tropical úmido ou subúmido $(\mathrm{Am})$, caracteriza-se por apresentar temperatura média do mês mais frio sempre superior a $18^{\circ} \mathrm{C}$ apresentando uma estação seca de pequena duração que é compensada pelos totais elevados de precipitação (GOLFARI et al., 1978; ALVARES, 2013; PEEL, 2007). Possuindo uma região climática úmida com os meses de setembro e outubro secos com predominância na maior parte do interior (oeste, sul, norte e toda a parte central) e a outra região úmida com os meses de setembro, outubro e novembro secos localizada na maior parte do litoral (AMAPÁ, 2009).

A cobertura florestal nativa do Amapá apresenta seis grandes tipologias de vegetação: florestas tropicais úmidas latifoliadas de folhagem permanente, cerrados, manguezais, restingas costeiras, lagoas e alagados de água doce ou salgada, e as florestas de palmeiras. As florestas do Amapá se subdividem em classes que possuem estruturas e floras diferentes, de acordo com a sua localização: montanas, submontanas, ciliares, de terras baixas não inundáveis e as de terras baixas inundáveis (DRUMMONT et al., 2008). O desmatamento em áreas de florestas encontra-se quase na sua totalidade às proximidades das principais rodovias do estado do Amapá e na área de transição floresta e não floresta. No biênio 2013-2014 a quantificação de desmatamento em área de floresta foi da ordem de $80,92 \mathrm{~km}^{2}$ e o total acumulado (de 1997 até 2014) de 2.768,36 km², o que corresponde a 2,5\% da área de floresta do Amapá (AMAPÁ, 2016).

\section{Obtenção dos dados}

Os dados sobre as autorizações de desmatamento foram obtidos no Núcleo de Documentação e Origem Florestal (NDOF), pertencente ao Instituto do Meio Ambiente e de Ordenamento Territorial (IMAP), 
em Macapá. Neste órgão, as autorizações de desmatamento são impressas e anexadas por ano. Cada autorização impressa foi consultada para extração das informações pertinentes ao estudo. A partir dessas informações um banco de dados foi elaborado em forma de planilha eletrônica.

Arquivos de extensão shapefile contendo os polígonos do desmatamento no Estado foram obtidos junto à SEMA, a qual gera dados bianuais do desmatamento para o Amapá. Assim, informações para os anos de 2013-2014 foram obtidas (AMAPÁ, 2016). Apesar da SEMA não gerar dados anuais sobre o desmatamento, seus dados foram utilizados por serem mais precisos, devido ao método empregado, que consiste na utilização de imagens de satélite em melhor resolução espacial e na identificação de áreas a partir de 0,1 ha.

Dados de desflorestamento gerados pelo Instituto Nacional de Pesquisas Espaciais (INPE), através do PRODES foram obtidos. Por serem dados anuais, foi possível comparar o impacto das autorizações para cada ano analisado. Os dados do INPE foram obtidos a partir de download dos arquivos shapefile ${ }^{1}$. Para possibilitar a observação da relação entre autorização e desmatamento foi criado um projeto SIG, contendo as seguintes informações em formato shapefile: limite municipal, desmatamento (SEMA e PRODES), autorização do desmatamento, malha viária, áreas protegidas, projetos de assentamentos e seus respectivos loteamentos.

\section{Espacialização das autorizações do desflorestamento}

Os dados de autorização, contidos na planilha, foram espacializados no programa ArcGIS, a partir das informações de suas coordenadas geográficas. Dessa forma, para cada autorização houve um ponto georreferenciado com suas respectivas atribuições: validade, ano, área autorizada, detentor, município e coordenadas.

Para identificação da área desmatada relacionada com cada autorização, foi feito um estudo detalhado para associar o desmatamento às autorizações, identificando qual área desmatada poderia estar associada a uma autorização. No caso dos assentamentos foi possível identificar o lote para o qual a autorização foi emitida. Identificado o lote, buscou-se dados sobre desmatamento em seu interior, o polígono foi associado à autorização do ano correspondente. Nos casos que não houve desmatamento em área autorizada, esta informação foi inserida na tabela de atributo do shapefile autorização.

\section{Análise dos dados}

A análise dos dados foi realizada através da comparação entre as áreas desmatadas e a espacialização dos polígonos de desmatamento relacionados às autorizações. Tabelas contendo a área total anual foram elaboradas para cada município da área autorizada para desmatamento, área do desmatamento legal e área do desmatamento ilegal. A partir das tabelas foram gerados os percentuais do desmatamento legal e ilegal para cada município. Mapas foram elaborados, contendo os desmatamentos legais e ilegais para o período

\footnotetext{
${ }^{1}$ http://www.obt.inpe.br/prodes/index.php 
estudado. A visualização desta questão permitiu diversas análises sobre a possível relação com variáveis geográficas, tais como a proximidade de estradas e assentamentos.

\section{RESULTADOS}

A Tabela 1 demonstra as estatísticas gerais das áreas autorizadas para o desmatamento. Evidenciase a maior área autorizada para os municípios de Pedra Branca do Amapari (1.551,02ha) e Ferreira Gomes (1.524,55ha). Dos 16 municípios, cinco não tiveram áreas autorizadas para desflorestamento no período estudado. Além disso, observa-se que o ano de 2014 houve o maior número de autorizações de desmatamento expedidas $(n=78)$, com 2.063,79ha autorizados para desmate.

Tabela 1: Total de áreas autorizadas para desflorestamento legal (ha) por municípios no biênio 2013-2014 para o estado do Amapá.

\begin{tabular}{|l|l|l|l|}
\hline \multirow{2}{*}{ Município } & $\mathbf{2 0 1 3}$ & $\mathbf{2 0 1 4}$ & \multirow{2}{*}{ Total por Município } \\
\cline { 2 - 3 } & IMAP (88)* & \multicolumn{1}{|l|}{ IMAP (78)* } \\
\cline { 2 - 3 } & Área Aut. (ha) & Área Aut. (ha) & \\
\hline PEDRA BRANCA DO AMAPARI & 395,10 & 1155,91 & 1551,02 \\
\hline FERREIRA GOMES & 799,55 & 725,00 & 1524,55 \\
\hline PORTO GRANDE & 68,30 & 139,87 & 208,17 \\
\hline OIAPOQUE & 96,54 & 7,00 & 103,54 \\
\hline TARTARUGALZINHO & 21,00 & 15,00 & 36,00 \\
\hline SERRA DO NAVIO & 9,00 & 6,00 & 15,00 \\
\hline MAZAGÃO & 6,00 & 6,00 & 12,00 \\
\hline MACAPA & 7,00 & 3,00 & 10,00 \\
\hline SANTANA & 7,11 & 0,00 & 7,11 \\
\hline AMAPÁ & 2,04 & 3,00 & 5,04 \\
\hline CALÇOENE & 0,00 & 3,00 & 3,00 \\
\hline CUTIAS DO ARAGUARI & 0,00 & 0,00 & 0,00 \\
\hline ITAUBAL DO PIRIRIM & 0,00 & 0,00 & 0,00 \\
\hline LARANJAL DO JARI & 0,00 & 0,00 & 0,00 \\
\hline PRACUÚBA & 0,00 & 0,00 & 0,00 \\
\hline VITORIA DO JARI & 0,00 & 0,00 & 0,00 \\
\hline Total por Ano & $\mathbf{1 4 1 1 , 6 4}$ & $\mathbf{2 0 6 3 , 7 9}$ & $\mathbf{3 4 7 5 , 4 2}$ \\
\hline
\end{tabular}

*Valor referente ao total de autorizações de desmatamento.

Conforme pode ser observado na Tabela 2 foram emitidas 166 autorizações, das quais 137 estavam hábeis a serem espacialmente localizadas com coordenadas geográficas (correspondendo a 3.401,43 ha), estando as outras 29 autorizações com coordenadas geográficas incompletas ou ausentes (74,00 ha), as quais, portanto, não constam na Figura 2.

Tabela 2: Quantidade e área de autorizações de desmatamento espacializados e não espacializados nos anos de 2013 e 2014.

\begin{tabular}{|c|c|c|c|c|c|}
\hline Fonte/Ano & $\begin{array}{ll}\text { Quantidade } & \text { de } \\
\text { Autorizações } & \\
\text { espacializadas } & \end{array}$ & $\begin{array}{lr}\text { Quantidade } & \text { de } \\
\text { Autorizações } & \text { não } \\
\text { espacializadas } & \\
\end{array}$ & $\begin{array}{l}\text { Área Autorizada } \\
\text { espacializada (ha) }\end{array}$ & $\begin{array}{lr}\text { Área } & \text { Autorizada } \\
\text { não } & \text { espacializada } \\
\text { (ha) } & \\
\end{array}$ & $\begin{array}{l}\text { Área } \quad \text { Total } \\
\text { Autorizada (ha) }\end{array}$ \\
\hline IMAP & \multirow[t]{2}{*}{63} & \multirow[t]{2}{*}{25} & \multirow[t]{2}{*}{1349,64} & \multirow[t]{2}{*}{62,00} & \multirow[t]{2}{*}{1411,64} \\
\hline 2013 & & & & & \\
\hline IMAP & \multirow[t]{2}{*}{74} & \multirow[t]{2}{*}{4} & \multirow[t]{2}{*}{2051,79} & \multirow[t]{2}{*}{12,00} & \multirow[t]{2}{*}{2063,79} \\
\hline 2014 & & & & & \\
\hline Subtotal & 137 & 29 & \multirow[t]{2}{*}{3401,43} & \multirow[t]{2}{*}{74} & \multirow[t]{2}{*}{3475,43} \\
\hline Total & \multicolumn{2}{|l|}{166} & & & \\
\hline
\end{tabular}




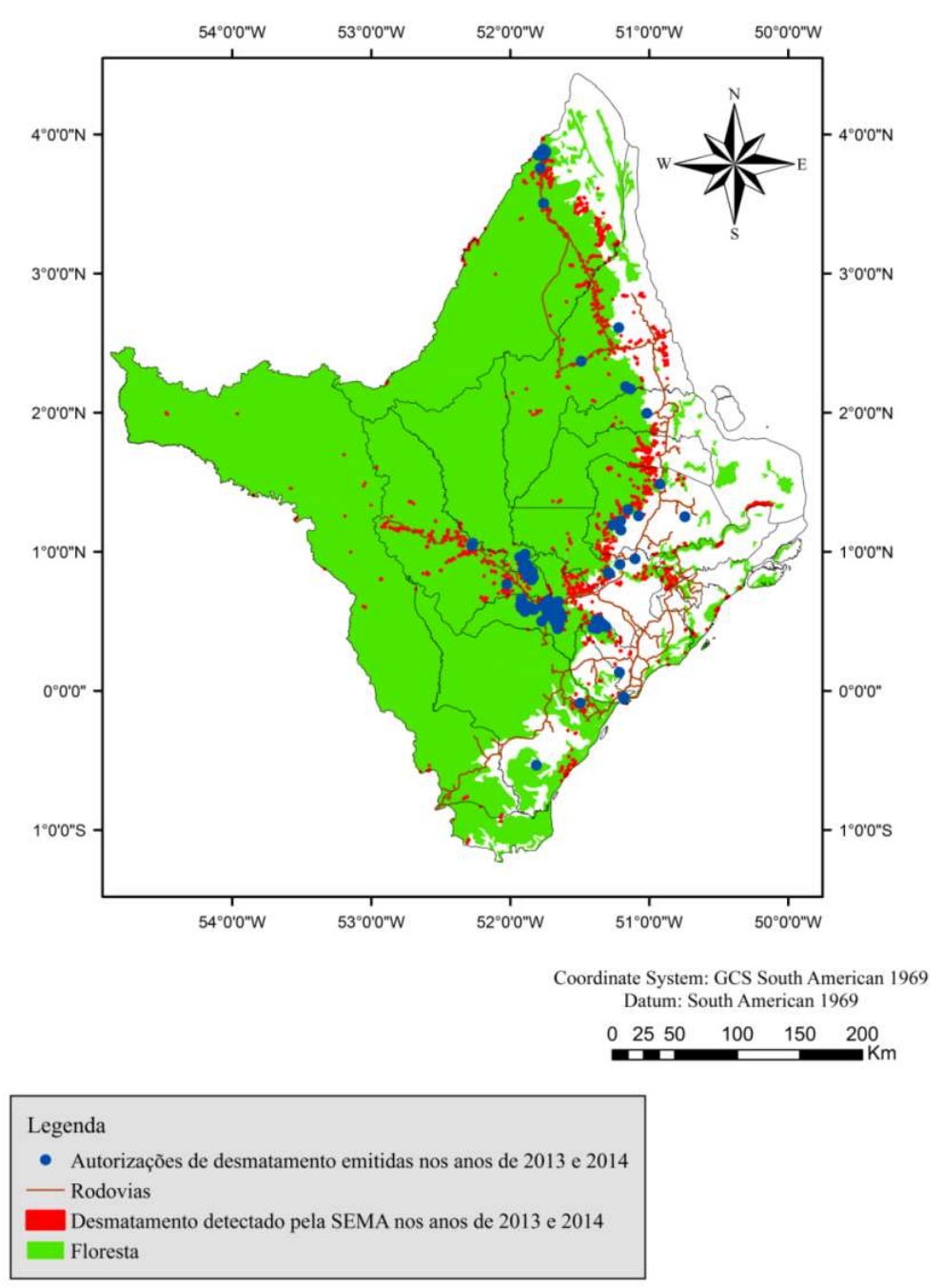

Figura 2: Dinâmica das autorizações de desmatamento.

A maior parte das áreas autorizadas (139 autorizações) apresentam dimensões inferiores ou iguais a 3 ha, que somam 509,61 ha, 20 apresentam de 3,1 a 99,9 ha, totalizando 576,80 ha e apenas sete encontramse definidas como iguais ou superiores a 100 ha, representando a maior área autorizada de 2.389,02 ha (Tabela 3). As autorizações que apresentam dimensões inferiores ou iguais a 3 ha, são características de projetos de assentamentos. Na Figura 3 podemos identificar que a dinâmica das autorizações de desmatamento segue os projetos de assentamentos.

Tabela 3: Tamanho das áreas autorizadas para desmatamento.

\begin{tabular}{|l|l|l|l|l|}
\hline Tamanho da área autorizada (hectares) & $\mathbf{5 3}$ & $\mathbf{5}$ a 9 & $\mathbf{1 0 0}$ & Total \\
\hline $\mathbf{N}^{\circ}$ de AD & $\mathbf{3}$ & $\mathbf{2 0}$ & $\mathbf{7}$ & $\mathbf{1 6 6}$ \\
\hline Área total de AD & 139 & 576,80 & 2389,02 & $\mathbf{3 4 7 5 , 4 2}$ \\
\hline
\end{tabular}

De acordo com a Tabela 4 no ano de 2013 o desmatamento autorizado representou 61,35\% do desmatamento detectado pelo PRODES/INPE. Em 2014 o desmatamento autorizado representou 66,58\%, superando o ano anterior. No período estudado o desmatamento autorizado alcançou $64,35 \%$, diferente do percentual de desmatamento autorizado em relação ao desmatamento detectado pela SEMA, que foi de 
50,13 \% (Tabela 5), isso ocorre devido a SEMA identificar áreas a partir de 0,10 ha, enquanto que o PRODES/INPE, área mínima mapeada é de 6,25 ha.

Tabela 4: Percentual das autorizações de desmatamento em relação aos desmatamentos detectados pelo PRODES/INPE no biênio 2013-2014.

\begin{tabular}{|l|l|l|l|l|}
\hline ANO & $\begin{array}{l}\text { Área Autorizada } \\
\text { IMAP }\left(\mathbf{K m}^{2}\right)\end{array}$ & $\begin{array}{l}\text { Desmatamento } \\
\text { detectado } \\
\text { PRODES/INPE }\left(\mathbf{K m}^{2}\right)\end{array}$ & $\begin{array}{l}\text { Percentual do } \\
\text { Autorizações } \\
\text { desmatamento (\%) }\end{array}$ & $\begin{array}{l}\text { Percentual de } \\
\text { desmatamento } \\
\text { Não Autorizado (\%) }\end{array}$ \\
\hline 2013 & 14,11 & 23,00 & 61,35 & 38,65 \\
\hline 2014 & 20,64 & 31,00 & 66,58 & 33,42 \\
\hline TOTAL & $\mathbf{3 4 , 7 5}$ & $\mathbf{5 4 , 0 0}$ & $\mathbf{6 4 , 3 5}$ & $\mathbf{3 5 , 6 5}$ \\
\hline
\end{tabular}

A Tabela 5 mostra que os municípios de Pedra Branca do Amapari e Ferreira Gomes tiveram as maiores áreas autorizadas para o desmate, mas não realizaram o desmatamento total que fora autorizado, devido as autorizações terem áreas acima de 100 ha para a supressão, fazendo com que o proprietário utilize o tempo máximo, ou seja, até o final da validade da autorização, que é de um ano, após sua emissão. Isso explica o fato de a área autorizada ser maior que a área detectada pela SEMA neste período. Enquanto que os municípios de Cutias do Araguari, Itaubal do Piririm, Pracuúba e Vitória do Jari desmataram sem autorização.

Tabela 5: Informações sobre as autorizações e desmatamento detectado em terras indígenas nos municípios no biênio 2013-2014.

\begin{tabular}{|l|l|l|l|l|l|}
\hline Município & $\begin{array}{l}\text { Área } \\
\text { Autorizada } \\
\text { IMAP (ha) }\end{array}$ & $\begin{array}{l}\text { Desmatamento } \\
\text { detectado pela } \\
\text { SEMA (ha) }\end{array}$ & $\begin{array}{l}\text { Desmatamento } \\
\text { detectado pela } \\
\text { SEMA em Terras } \\
\text { Indígenas (ha) }\end{array}$ & $\begin{array}{l}\text { Percentual das } \\
\text { autorizações de } \\
\text { desmatamento } \\
\text { (\%) }\end{array}$ & $\begin{array}{l}\text { Percentual do } \\
\text { desmatamento } \\
\text { Não autorizado } \\
\text { (\%) }\end{array}$ \\
\hline $\begin{array}{l}\text { CUTIAS DO } \\
\text { ARAGUARI }\end{array}$ & 0,00 & 203,00 & - & 0,00 & 100,00 \\
\hline ITAUBAL DO PIRIRIM & 0,00 & 41,00 & - & 0,00 & 100,00 \\
\hline LARANJAL DO JARI & 0,00 & 39,43 & 10,57 & 0,00 & 100,00 \\
\hline PRACUÚBA & 0,00 & 841,00 & - & 0,00 & 100,00 \\
\hline VITORIA DO JARI & 0,00 & 23,00 & - & 0,00 & 100,00 \\
\hline CALÇOENE & 3,00 & 1190,00 & - & 0,25 & 99,75 \\
\hline MACAPA & 10,00 & 517,00 & - & 1,93 & 98,07 \\
\hline TARTARUGALZINHO & 36,00 & 1618,00 & - & 2,22 & 97,78 \\
\hline AMAPÁ & 5,04 & 87,00 & - & 5,79 & 94,21 \\
\hline MAZAGÃO & 12,00 & 162,00 & - & 7,41 & 92,59 \\
\hline SANTANA & 7,11 & 46,00 & - & 15,46 & 84,54 \\
\hline OIAPOQUE & 103,54 & 445,00 & 861,00 & 23,27 & 76,73 \\
\hline PORTO GRANDE & 208,17 & 564,00 & - & 36,91 & 63,09 \\
\hline SERRA DO NAVIO & 15,00 & 36,00 & - & 41,67 & 58,33 \\
\hline FERREIRA GOMES* & 1524,55 & 366,00 & - & - & - \\
\hline $\begin{array}{l}\text { PEDRA BRANCA DO } \\
\text { AMAPARI* }\end{array}$ & 1551,02 & 790,57 & 249,43 & $-19,87$ & - \\
\hline Subtotal & & & 1121,00 & 50,13 \\
\hline Total & 3475,42 & 6969,00 & 8090,00 & & \\
\hline
\end{tabular}

*Municípios que possuem uma área autorizada maior do que o desmatamento detectado pela SEMA.

Oiapoque, Pedra Branca do Amapari e Ferreira Gomes tiveram desmatamento em terras indígenas (Figura 3), somando 1.121,00 ha de supressão. Com relação ao desmatamento em terras indígenas, não foram contabilizados no desmatamento total do estado do Amapá. O presente trabalho tomou por base os artigos 231 e 232 da Constituição Federal, que dispõe as terras indígenas, bens da União de regime especial, 
cabendo aos povos indígenas sua posse permanente e o usufruto exclusivo dos recursos naturais, tendo por propósito prover continuadamente os meios para a reprodução física e cultural dos povos indígenas.

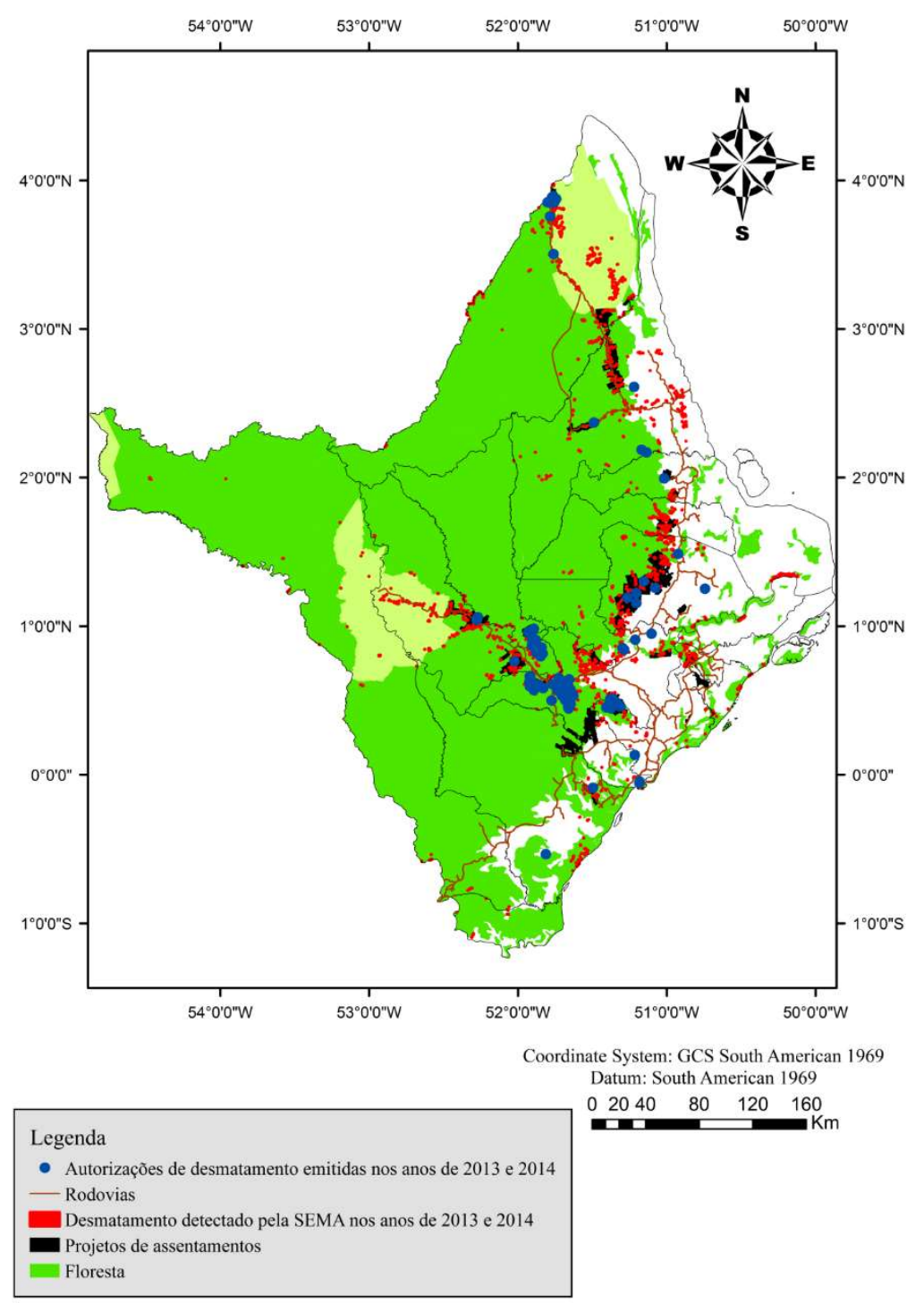

Figura 2: Desmatamento em Terras Indígenas.

\section{DISCUSSÃO}

Em 1997, o IBAMA autorizou o desmate de $8,1 \mathrm{~km}^{2}$ e foi detectada através de imagens de satélites pelo INPE, uma área de $18 \mathrm{~km}^{2}$ de desflorestamento, ou seja, a área não autorizada correspondeu aproximadamente a 55\% do desmatamento total no estado do Amapá (BRASIL, 2003). No ano de 1998, foi autorizado o desmatamento de $8,4 \mathrm{~km}^{2}$, representou $28 \%$ do total de desflorestamento informado pelo INPE, consequentemente $72 \%$ de desmatamento ilegal. Em relação ao ano de 1999, o IBAMA emitiu autorizações de desmatamento totalizando aproximadamente $20 \mathrm{~km}^{2}$, sendo que o INPE não conseguiu realizar o levantamento de desmatamento, devido a ocorrência de muitas nuvens (BRASIL, 2003).

Conforme os resultados obtidos nas tabelas 1, 2 e 3, a maior parte das autorizações de desmatamento detectado é de até 3 ha (139 autorizações), que somaram 509,61 ha, do total de 166 autorizações, as quais são características de projetos de assentamentos. 
Os assentamentos são os principais causadores de desflorestamento na Amazônia nos últimos anos (FEARNSIDE, 1999; 2001). O desflorestamento tem sido destacado principalmente pela mudança no tamanho dos polígonos, passando de grande para pequenas áreas (ALENCAR et al., 2016; MMA, 2013). Para Alencar et al. (2016), as áreas de polígonos de floresta desmatadas no período de 2010 a 2014 no estado do Amapá, foram de pequenas áreas, realizadas em até 10 ha.

No estado do Amapá, a agricultura familiar nos projetos de assentamentos, contribui com grande parte na taxa de desmatamento, através de revezamento de terras (DOMINGUES et al., 2004; AMAPÁ, 2009). Este revezamento correlacionado com a variação da área produz constante desmate e queimada, caracterizando o chamado desmatamento silencioso, que são difíceis de serem detectados por imagens de satélites (DOMINGUES et al., 2004).

De acordo pesquisa realizada por Batista (2009), para o período compreendido entre os anos 2001 a 2006, os desmatamentos ocorridos nos projetos de assentamentos, principalmente, os de jurisdição do Instituto Nacional de Colonização e Reforma Agrária (INCRA-AP), representou um percentual de $25,5 \%$ (38.358 ha) do total de áreas desmatadas no estado do Amapá.

Assim como em outros estudos (AMAPÁ, 2016; COSTA, 2017a), a estimativa de desmatamento nos assentamentos vem crescendo. No biênio 2013-2014, o desmatamento foi de 21,27km², sendo que, a maior incidência de desmatamentos ocorreu nos assentamentos localizados na região central e ao norte do estado (AMAPÁ, 2016). Segundo Costa (2017a), em um estudo realizado para analisar o impacto do desflorestamento legal no projeto de assentamento Cedro, no município de Tartarugalzinho, nos anos de 2009 a 2014, o autor concluiu que 92,89\% do desmatamento, no assentamento foi realizado sem autorização do órgão competente.

Atualmente, o desflorestamento na Amazônia Legal é monitorado através de imagens de satélites LANDSAT, CBERS e MODIS, pelo Programa de Monitoramento da Amazônia por Sensoriamento Remoto do INPE. Neste programa encontra-se o Projeto de Monitoramento de Desflorestamento na Amazônia Legal (PRODES) que realiza o monitoramento desde 1988, estimando taxas anuais de desmatamento na região amazônica (CÂMARA et al., 2006; INPE, 2008).

A partir do ano de 2002, foi implantada uma nova metodologia que anteriormente era de apenas na interpretação das imagens, passando a verificar também a classificação digital das imagens. O PRODES permitiu a divulgação das estimativas anuais com os polígonos de desflorestamento, representando o incremento da área que sofreu o desflorestamento (INPE, 2008).

No estado de Mato Grosso, em 2016, de todo o desmatamento identificado pelo INPE, $1.508 \mathrm{~km}^{2}$, $95 \%$ correspondeu ao desmatamento ilegal, que chegou a $1.440 \mathrm{~km}^{2}$, apenas $68,8 \mathrm{~km}^{2}$ (4,6 \%) foi realizado em áreas com autorização de desmatamento (ICV, 2017). Mato Grosso foi o segundo estado com maior área desmatada, ficando atrás apenas do estado do Pará, que converteu $3.025 \mathrm{~km}^{2}$ de florestas em área desmatada.

De acordo com os resultados das tabelas 4 e 5, nos anos de 2013 e 2014 o desflorestamento ilegal chegou a 50,13\%, que correspondeu aproximadamente a $35 \mathrm{~km}^{2}$, ou seja, mais da metade do 
desflorestamento detectado pela SEMA foi realizado ilegalmente no estado do Amapá. Mas, se comparado com os dados do INPE, de um total de $54 \mathrm{~km}^{2}$, a taxa de desmatamento ilegal reduziu para 35,65\%, correspondente apenas a $19,25 \mathrm{~km}^{2}$, isso ocorreu devido utilizarem metodologias diferentes.

Apesar de ambos os órgãos empregarem os mesmos dados de sensoriamento remoto como insumo principal da análise do desmatamento, as metodologias utilizadas são diferentes, o que resulta na geração de dados e informações diferenciadas, como pode-se observar no desmatamento detectado pelo INPE e SEMA, no período estudado. A fundamental diferença metodológica está na Unidade Mínima de Mapeamento (LUZ, 2002; AMAPÁ, 2014; ANDERSON, 2015).

Enquanto que a SEMA identifica a área desmatada do tipo corte raso e também alterações da cobertura florestal em geral, em áreas superiores a 0,10 ha, o Projeto PRODES/INPE detecta unicamente o desmatamento onde é realizado o corte raso da floresta em áreas superiores a 6,25 ha. Tal escala tende a mascarar áreas desmatadas, especialmente, em lotes existentes nos projetos de assentamentos, onde levam, em média, de 2 a 3 anos consecutivos para desmatar tal quantitativo (BATISTA, 2009).

Um entrave, é que a estimativa da taxa de desmatamento utiliza apenas imagens ópticas e que a existência de nuvens dificulta a coleta e interpretação dos focos de desmatamentos. Isto por que, entre os estados da Amazônia Legal, o Amapá é o que apresenta a maior média de proporção de cobertura de nuvens por ano (ASNER, 2001). Porém a busca pela imagem é feita para todo o acervo anual disponível, a fim de obter as imagens com menor quantidade de nuvens para cada cena, enquanto o PRODES usualmente utiliza imagens do mês de agosto. Por conta disto, as taxas bianuais da SEMA se referem às alterações observadas na melhor imagem do período estimado (AMAPÁ, 2014). Em 2009 e 2010, os municípios de Calçoene, Oiapoque, Cutias do Araguari e Pracuúba desmataram, respectivamente, 1.816,95 ha, 1.554,27 ha, 130 ha e 53 ha, todos sem autorização de desmatamento (COSTA et al., 2017b).

Neste estudo, conforme tabela 5, os municípios de Pedra Branca do Amapari e Ferreira Gomes tiveram as maiores áreas autorizadas para o desmate, mas não realizaram o desmatamento total. Isso explica o fato de a área autorizada ser maior que a área detectada pela SEMA neste período. Enquanto que os municípios de Cutias do Araguari, Itaubal do Piririm, Pracuúba e Vitória do Jari desmataram sem autorização. Se comparado com o estudo realizado nos anos de 2009 e 2010, os municípios de Cutias do Araguari e Pracuúba vêm desmatando sem autorização.

Podemos citar ainda, que os municípios de Oiapoque, Pedra Branca do Amapari e Ferreira Gomes tiveram desmatamento em terras indígenas (Figura 3). Todas as atividades que envolvam a exploração dos recursos naturais são permitidas unicamente no âmbito do exercício do direito ao usufruto exclusivo garantido aos povos indígenas por força da Constituição Federal. Importa dizer que, somente os indígenas podem usufruir dos recursos naturais existentes em seus respectivos territórios tradicionais, afastando das terras indígenas os procedimentos previstos na legislação ambiental para licenciamento ou autorização das atividades econômicas que envolvam exploração de recurso madeireiros, vez que os bens naturais existentes nos territórios são voltados à sustentabilidade de seus detentores. 


\section{CONCLUSÕES}

Conclui-se que a geotecnologia é uma ferramenta de destaque devido a sua funcionalidade, demonstrando a possibilidade e necessidade da aplicação de geoprocessamento para a análise do desmatamento legal, através da espacialização das autorizações de desmatamento, de maneira com que as informações sejam precisas. Nesse contexto, SIG como ferramenta de subsidio na tomada de decisão mostrase ser um importante instrumento que traz resultados relevantes.

Com a aplicação de técnicas de geoprocessamento foi possível espacializar as autorizações de desmatamento, resultando na identificação e análise do desmatamento não autorizado no Estado do Amapá, quantificando-o, no período estudado. Tal resultado mostra que 50,13\%, que correspondeu a $3.493,58$ hectares, ou seja, mais da metade do desflorestamento detectado pela Secretaria de Estado e Meio Ambiente foi realizado ilegalmente no estado do Amapá, anos de 2013 e 2014.

O presente estudo, destaca que a metodologia pode ser replicada e os resultados gerados de acordo com a análise da dinâmica do desmatamento legal nos municípios do Estado do Amapá nos anos de 2013 e 2014, que identificou os municípios que possuem as maiores taxas de desmatamento não autorizado, auxiliem as autoridades competentes em tomada de decisões que envolve o desmatamento ilegal e que aplicações de políticas públicas sejam utilizadas para minimizar e até mesmo erradicar o desmatamento ilegal naquela região e que possam ser objeto de novos estudos.

\section{REFERÊNCIAS}

ALENCAR, A.; PEREIRA, C.; CASTRO, I.; CARDOSO, A.; SOUZA, L.; COSTA, R.; BENTES, A. J.; STELLA, O.; AZEVEDO, A.; GOMES, J.; NOVAES, R.. Desmatamento nos Assentamentos da Amazônia: Histórico, Tendências e Oportunidades. Brasília: IPAM, 2016.

ALVARES, C. A.; STAPE, J. L.; SENTELHAS, P. C.; GONSALVES, J. L. M.; SPAROVEK, G.. Ko"ppen's climate classification map for Brazil. Meteorologische Zeitschrif, Berlim, v.22, n.6, p.711-728, 2013. DOI: https://dx.doi.org/10.1127/0941$\underline{2948 / 2013 / 0507}$

ANDERSON, A.. Diretrizes de um Programa de REDD+ para o Estado do Amapá. Macapá: Instituto Estadual de Florestas do Amapá, 2015.

AMAPÁ. Relatório Técnico de Desmatamento no Estado do Amapá, referente a 2004. Macapá: Secretaria de Estado do Meio Ambiente, 2005.

AMAPÁ. Programa de Prevenção e Controle do Desmatamento e Queimadas do Estado do Amapá PPCDAP. Macapá: Secretaria Especial de Desenvolvimento Econômico do Estado e Secretaria de Estado do Meio Ambiente, 2009.

AMAPÁ. Relatório Técnico de Desmatamento no Estado do Amapá referente ao período 2007 a 2008. Macapá: Secretaria de Estado do Meio Ambiente, 2010.
AMAPÁ. Relatório Técnico de Desmatamento no Estado do Amapá, referente ao período 2011 a 2012. Macapá: Secretaria de Estado do Meio Ambiente, 2014.

AMAPÁ. Plano Anual de Outorga Florestal 2015. Macapá: Instituto Estadual de Florestas do Amapá. Macapá: IEF/AP, 2014.

AMAPÁ. Relatório Técnico de Desmatamento no Estado do Amapá, referente ao período 2013 a 2014. Macapá: Secretaria de Estado do Meio Ambiente, 2016.

ASNER, G. P.. Cloud cover in Landsat observations of the Brazilian Amazon. International Journal of Remote Sensing, Bristol, v.22, n.18, p.3855-3862, 2001. DOI: http://dx.doi.org/10.1080/01431160010006926

BATISTA, E. M.. O desmatamento em Projetos de Colonização e Reforma Agrária situados no Estado do Amapá. In: SIMPÓSIO BRASILEIRO DE SENSORIAMENTO REMOTO, 19. Anais. Natal: Centro de Convenções, 2009.

BRASIL. Informativo técnico: Desmatamento. Brasília: Ministério do Meio Ambiente. IBAMA, 2003.

CÂMARA, G.; VALERIANO, D. M.; SOARES, J. V.. Metodologia para o Cálculo da Taxa Anual de Desmatamento na Amazônia Legal. São José dos Campos: INPE, 2006.

COSTA, J. D. M.. Análise espacial do desflorestamento legal e ilegal no projeto de assentamento Cedro no município de Tartarugalzinho no estado do Amapá. In: SIMPÓSIO 
BRASILEIRO DE SENSORIAMENTO REMOTO, 18. Anais. Santos: Mendes Convention Center, 2017a.

COSTA, J. D. M.; CARMONA, S. L. S.; FUNI, C.. Análise espacial do desflorestamento legal no estado do Amapá. In: SIMPÓSIO BRASILEIRO DE SENSORIAMENTO REMOTO, 18. Anais. Santos: Mendes Convention Center, 2017b.

ICV. Instituto Centro de Vida. Análise do desmatamento em Mato Grosso (Prodes/2016). Cuiabá: ICV, 2017.

DOMINGUES, E.; PEREIRA, R. F.; GAMA, A. M. R. C.; RIBEIRO, G. V.; ALVES, P. S. P. F.; FERNANDES, N. P.; LEITE, P. F.; GOMES, S. O.; AQUINO, A. M. F. A.; LIMA, S. S. C.. Cobertura e Uso da Terra no Estado do Amapá. Rio de Janeiro: IBGE, 2004.

DRUMMOND, J. A.; DIAS, T. C. A. C.; BRITO, D. M. C.. Atlas das Unidades de Conservação do Estado do Amapá. Macapá: MMA/IBAMA-AP; GEA/SEMA, 2008.

FEARNSIDE, P. M.. Combate ao desmatamento na Amazônia brasileira. In: Instituto Ambiental do Paraná. Cadernos da Biodiversidade, Curitiba, v.2, n.2, p.12-29, 1999.

FEARNSIDE, P. M.. Land-Tenure Issues as Factors in Environmental Destruction in Brazilian Amazonia: the case of southern Pará. World Development, v.29, n.8, p.1361-1372, 2001. DOI: https://doi.org/10.1016/S0305-750X(01)00039-0

FLORENZANO, T. G.. Geomorfologia: conceitos e tecnologias atuais. São Paulo: Oficina de Textos, 2008.

GOLFARI, L.; CASER, R. L.; MOURA, V. P. G.. Zoneamento ecológico esquemático para reflorestamento no Brasil. Belo Horizonte: PRODEPEF, 1978.

INPE. Instituto Nacional de Pesquisas Espaciais. Monitoramento da cobertura florestal da Amazônia por satélites: sistemas PRODES, DETER, DEGRAD E QUEIMADAS 2007-2008. São José dos Campos: INPE, 2008.

INPE. Instituto Nacional de Pesquisas Espaciais. Projeto PRODES - divulgação da taxa estimada do desmatamento da Amazônia Legal para período ago./2014-jul./2015. São José dos Campos: INPE, 2015.

IBGE. Instituto Brasileiro de Geografia e Estatística. Censo Demográfico 2010. Rio de Janeiro: IBGE, 2012.

KITAMURA, P. C.. A Amazônia e o Desenvolvimento Sustentável, São Paulo: Embrapa, 1994.

LEMOS, A. L. F.; SILVA, J. A.. Desmatamento na Amazônia Legal: evolução, causa, monitoramento e possibilidades de mitigação através do fundo Amazônia. Floresta e Ambiente, Rio de Janeiro, v.18, n.1, p.98-108, 2011. DOI: http://doi.org/10.4322/floram.2011.027

LUZ, N.. Análise espacial como subsídio à recuperação de ecossistemas apoiada na ecologia de paisagens e imagens Ikonos. Dissertação (Mestrado em Engenharia Florestal) Universidade Federal do Paraná, Curitiba, 2002.

MMA. Plano de Ação para Prevenção e Controle do desmatamento na Amazônia Legal - PPCDAM 1a fase. Brasília: Ministério do Meio Ambiente, 2004.

MMA. 2013. Plano de Ação para prevenção e controle do desmatamento na Amazônia Legal - PPCDAM 3a fase. Brasília: Ministério do Meio Ambiente, 2013.

PEEL, M. C.; FINLAYSON, B. L.; MCMAHON, T. A.. Updated world map of the Ko" ppen-Geiger climate classification. Hydrology and Earth System Sciences Discussions, Berlim, v.11, n.5, p.1633-1644, 2007. DOI: https://doi.org/10.5194/hess-11-1633-2007

A CBPC - Companhia Brasileira de Produção Científica (CNPJ: 11.221.422/0001-03) detém os direitos materiais desta publicação. Os direitos referem-se à publicação do trabalho em qualquer parte do mundo, incluindo os direitos às renovações, expansões e disseminações da contribuição, bem como outros direitos subsidiários. Todos os trabalhos publicados eletronicamente poderão posteriormente ser publicados em coletâneas impressas sob coordenação da Sustenere Publishing, da Companhia Brasileira de Produção Científica e seus parceiros autorizados. Os (as) autores (as) preservam os direitos autorais, mas não têm permissão para a publicação da contribuição em outro meio, impresso ou digital, em português ou em tradução. 